\title{
Influence of diabetes on the loss of beta cell differentiation after islet transplantation in rats
}

\author{
D. R. Laybutt • Y. C. Hawkins • J. Lock • J. Lebet • \\ A. Sharma $\cdot$ S. Bonner-Weir $\cdot$ G. C. Weir
}

Received: 7 May 2007 / Accepted: 30 May 2007 / Published online: 20 July 2007

(C) Springer-Verlag 2007

\begin{abstract}
Aims/hypothesis Hyperglycaemia can impair beta cell function after islet transplantation. Appropriate glucose-induced insulin secretion is dependent on a unique expression pattern of genes. Here we examined the effects of diabetes on gene expression in transplanted islets.

Materials and methods Streptozotocin-induced diabetic or control non-diabetic Lewis rats were transplanted under the kidney capsule with an insufficient number $(2,000)$ of syngeneic islets to normalise blood glucose levels in diabetic rats. Eighteen days after transplantation, islet grafts were retrieved and RT-PCR used to assess expression of selected genes critical for beta cell function. Islet grafts from diabetic rats transplanted with a sufficient number of islets $(3,000)$ to normalise hyperglycaemia were used to assess the effects of correcting blood glucose levels. Additionally, gene expression of transplanted islets from non-diabetic rats was compared with freshly isolated islets.
\end{abstract}

Electronic supplementary material The online version of this article (doi:10.1007/s00125-007-0749-2) contains supplementary material, which is available to authorised users.

D. R. Laybutt • Y. C. Hawkins · J. Lock · J. Lebet • A. Sharma •

S. Bonner-Weir $\cdot$ G. C. Weir $(\bowtie)$

Section of Islet Transplantation and Cell Biology,

Research Division, Joslin Diabetes Center,

Harvard Medical School,

One Joslin Place,

Boston, MA 02215, USA

e-mail: Gordon.Weir@joslin.harvard.edu

D. R. Laybutt

Diabetes and Obesity Research Program,

Garvan Institute of Medical Research, St Vincent's Hospital,

Sydney, NSW, Australia
Results In islet grafts from diabetic rats, mRNA levels of several transcription factors important for the maintenance of beta cell differentiation were reduced (pancreatic and duodenal homeobox $1[P d x l]$, neurogenic differentiation 1 [Neurod1], NK6 transcription factor related, locus 1 [Nkx6.1], paired box gene $6[$ Pax 6$]$ ), as were genes implicated in beta cell function (Glut2 [also known as solute carrier family 2 [facilitated glucose transporter], member 2 [Slc2a2], glucokinase, insulin, islet amyloid polypeptide [Iapp]). Conversely, mRNA levels of lactate dehydrogenase, which is normally suppressed in beta cells, were increased. The majority of the changes in gene expression were normalised after correction of hyperglycaemia, indicating that the severe loss of beta cell differentiation correlates with continuous exposure to diabetes. Even islet grafts from non-diabetic rats showed a few alterations in beta cell gene expression in comparison with fresh islets.

Conclusions/interpretation Chronic hyperglycaemia contributes to the deterioration of beta cell differentiation after islet transplantation.

Keywords Diabetes · Differentiation - Gene expression . Glucotoxicity · Insulin secretion · Islets .

Pancreatic beta cells . Transplantation

\begin{tabular}{|c|c|}
\hline \multicolumn{2}{|c|}{ Abbreviations } \\
\hline cDNA & complementary DNA \\
\hline GIIS & glucose-induced insulin secretion \\
\hline NKX6.1 & NK6 transcription factor related, locus 1 \\
\hline
\end{tabular}

\section{Introduction}

A major defect in insulin secretory function is found in all forms of diabetes and in recipients of islet transplants [1-4]. 
The most striking defect is a selective loss of glucoseinduced insulin secretion (GIIS), whereas responses to other secretory stimuli are less severely impaired [5-7]. Despite its fundamental importance to diabetes pathology, the underlying mechanism(s) for the loss of GIIS remain(s) unknown.

Recent progress in islet transplantation has demonstrated sustained C-peptide production and successful insulin independence in type 1 diabetic patients [8]. Large numbers of islets are needed because of extensive islet cell death in the peri-transplant period and functional impairment in part due to islets residing in an abnormal environment [9-13]. With time, islet function is lost again, such that most patients revert to the use of exogenous insulin within 2 years [14]. It is therefore essential to better understand islet function in the post transplantation period.

Sustained hyperglycaemia has a detrimental impact on the glycaemic outcome of islet transplantation and upon preservation of the graft $[5,7,10,15-17]$. The usual outcome of islet transplantation in humans is glucose intolerance and the deterioration of glycaemic control over time $[9,12,14]$, which may be due to the toxic effects of hyperglycaemia upon islet function, a phenomenon called glucotoxicity. We hypothesised that inadequate insulin secretion in an islet graft is caused by a loss of the unique expression pattern of genes responsible for maintaining GIIS. In this study, we examined the effects of hyperglycaemia on beta cell differentiation in transplanted islets. We also compared gene expression in islet grafts with that in freshly isolated islets.

\section{Materials and methods}

Animals and induction of diabetes Male inbred Lewis rats weighing 150 to $200 \mathrm{~g}$ were obtained from Taconic Farms (Germantown, NY, USA) and used both as islet donors and recipients. Animals were kept under conventional conditions with free access to water and standard pelleted food. All animal procedures were approved by the Joslin Diabetes Center Animal Care Committee. Graft recipients were either normal or diabetic rats. Rats were made diabetic by a single intraperitoneal dose of streptozotocin $(65 \mathrm{mg} / \mathrm{kg}$ body weight, dissolved in citrate buffer $\mathrm{pH} 4.5$; Sigma, St Louis, MO, USA). Before transplantation, diabetes was confirmed by the presence of hyperglycaemia $(19.4 \mathrm{mmol} / \mathrm{l})$ for at least 1 week. Blood was collected from the tail tip of rats to determine blood glucose levels measured with a portable glucometer (Medisense Precision QID; Abbott Laboratories, Bedford, MA, USA). To assess the effects of continuous exposure to diabetes on beta cell differentiation in transplanted islets, 2,000 islets (an insufficient number to reverse hyperglycaemia) were transplanted under the kidney capsule of normal or diabetic rats. To assess the effects of reversing hyperglycaemia after islet transplantation, 3,000 islets were transplanted under the kidney capsule of diabetic rats and compared with those of normal or diabetic rats transplanted with 2,000 islets. To assess the effects of transplantation alone, islet grafts from normal (non-diabetic) rats were compared with freshly isolated islets. Rats were weighed and bled for blood glucose levels on days 7, 14 and 18 after transplantation. Eighteen days after transplantation, islet grafts were retrieved and prepared for analysis.

Islet isolation Islets were isolated from Lewis rats as previously described [12]. Briefly, the pancreatic duct was distended with $10 \mathrm{ml}$ of M-199 medium (Gibco BRL, Grand Island, NY, USA) containing $1.5 \mathrm{mg}$ of collagenase (type P; Boehringer Mannheim, Mannheim, Germany). The pancreas was dissected and incubated in a stationary water bath at $37^{\circ} \mathrm{C}$. After digestion, the islets were separated on a density gradient (Histopaque-1077; Sigma, St Louis, MO, USA) and handpicked under a stereomicroscope. Islets were cultured for $24 \mathrm{~h}$ in RPMI containing $11.1 \mathrm{mmol} / 1$ glucose supplemented with $10 \%$ FCS, penicillin $(100 \mathrm{U} / \mathrm{ml})$ and streptomycin $(100 \mu \mathrm{g} / \mathrm{ml})$ in standard humidified culture conditions of $5 \% \mathrm{CO}_{2}$ and $95 \%$ air at $37^{\circ} \mathrm{C}$.

Transplantation Aliquots of either 2,000 or 3,000 islets were aspirated into pipette tips connected to a $1 \mathrm{ml}$ Hamilton syringe (Hamilton Company, Reno, NV, USA) and then transferred into P-50 polyethylene tubing. Islets were transplanted under the kidney capsule of normal or diabetic recipients as described previously [10]. Grafts were retrieved 18 days after transplantation by excising the portion of the kidney capsule with the graft adhering to it. Using great care, the graft was then removed from the capsule, cut into small fragments and suspended in RNA isolation solution. To assess possible contamination of the grafts with renal parenchymal tissue, expression of the kidney-specific organic anion transporter, solute carrier family 22 (organic anion transporter), member 6 (Slc22a6) [18] was measured.

$R N A$ extraction and synthesis of complementary DNA Total RNA was extracted from islet grafts and freshly isolated islets using Ultraspec RNA isolation reagent according to manufacturer-suggested protocols (Biotecx Laboratories, Houston, TX, USA). Following quantification by spectrophotometry, RNA (500 ng) was reverse-transcribed into complementary DNA (cDNA) in a final reaction solution of $25 \mu \mathrm{l}$ containing the following: $1 \times$ Superscript first-strand buffer ( $50 \mathrm{mmol} / 1 \mathrm{Tris}-\mathrm{HCl}, 75 \mathrm{mmol} / \mathrm{l} \mathrm{KCl}$ and $3 \mathrm{mmol} / \mathrm{l} \mathrm{MgCl} 2$; Life Technologies, Grand Island, NY, USA), 40 U Rnasin (Promega, Madison, WI, USA), $10 \mathrm{mmol} / 1$ dithiothreitol, $1 \mathrm{mmol} / \mathrm{l} \mathrm{dNTP,} 50 \mathrm{ng}$ of random hexamers and $200 \mathrm{U}$ of 
Superscript II Rnase $\mathrm{H}^{-}$reverse transcriptase (Life Technologies). RT reactions were incubated for $10 \mathrm{~min}$ at $25^{\circ} \mathrm{C}, 60 \mathrm{~min}$ at $42^{\circ} \mathrm{C}$ and $10 \mathrm{~min}$ at $95^{\circ} \mathrm{C}$. Resultant cDNA products were diluted with $50 \mu \mathrm{H}_{2} \mathrm{O}$ to a concentration corresponding to $10 \mathrm{ng}$ of starting RNA per $1.5 \mu \mathrm{l}$ and were stored at $-20^{\circ} \mathrm{C}$.

Semiquantitative radioactive multiplex polymerase chain reaction Polymerase chain reactions (PCR) were carried out in a volume of $25 \mu \mathrm{l}$ consisting of 10 to $20 \mathrm{ng}$ of cDNA, $1 \times$ GeneAmp PCR Gold buffer (Applied Biosystems, Foster City, CA, USA), 1 to $1.5 \mathrm{mmol} / 1 \mathrm{MgCl}_{2}, 80$ to $160 \mu \mathrm{mol} / \mathrm{l} \mathrm{dNTP}, 100$ to $400 \mathrm{nmol}$ of oligonucleotide primers (Sigma Genosys, St Louis, MO, USA), $46.25 \mathrm{kBq}$ of $\alpha-{ }^{32}$ P-labelled dCTP $(111 \mathrm{TBq} / \mathrm{mmol}$; New England Nuclear, Boston, MA, USA) and 2.5 U of AmpliTaq Gold DNA Polymerase (Applied Biosystems). For specific concentrations of $\mathrm{MgCl}_{2}$, dNTP and oligonucleotide primers, along with multiplex PCR conditions for each gene tested, see Electronic supplementary material (ESM) Table 1. Reactions were performed in a 9700 Thermocycler (Applied Biosystems), in which samples underwent a 10 min initial denaturing step, followed by the number of cycles indicated (ESM Table 1) for durations of $1 \mathrm{~min}$ at $94^{\circ} \mathrm{C}, 1 \mathrm{~min}$ at the annealing temperature indicated in ESM Table 1 and $1 \mathrm{~min}$ at $72^{\circ} \mathrm{C}$. The final extension step was $10 \mathrm{~min}$ at $72^{\circ} \mathrm{C}$. In each reaction, gene products of interest

Table 1 Comparison of islet-associated transcription factor and beta cell function mRNA levels in islet grafts from normal and diabetic rats

\begin{tabular}{lll}
\hline & Normal & Diabetic \\
\hline Characteristics & & \\
Body weight (g) & $284 \pm 12$ & $267 \pm 13$ \\
Blood glucose (mmol/l) & $5.7 \pm 0.1$ & $18.3 \pm 0.8^{* * *}$ \\
Transcription factors & & \\
Neurod1 & $100 \pm 6$ & $39 \pm 6^{* * *}$ \\
Pdx1 & $100 \pm 29$ & $39 \pm 4^{*}$ \\
Pax6 & $100 \pm 25$ & $28 \pm 6^{* *}$ \\
Nkx6.1 & $100 \pm 20$ & $50 \pm 4^{*}$ \\
Metabolism & & \\
Glut2 & $100 \pm 9$ & $64 \pm 9^{*}$ \\
Glucokinase & $100 \pm 16$ & $50 \pm 8^{*}$ \\
Hexokinase-1 & $100 \pm 27$ & $95 \pm 17$ \\
Ldha & $100 \pm 22$ & $260 \pm 49^{*}$ \\
Glucose-6-phosphatase & $100 \pm 34$ & $452 \pm 203$ \\
Ion channel & & \\
Kcnj11 & $100 \pm 39$ & $59 \pm 8$ \\
Hormones & & \\
Insulin & $100 \pm 16$ & $16 \pm 3 * * *$ \\
Iapp & $100 \pm 2$ & $81 \pm 4 * *$ \\
\hline
\end{tabular}

Values are mean $\triangle \mathrm{SEM}$ determined from three to six experiments and are expressed as a percentage of mRNA levels in islet grafts from normal rats

${ }^{*} p<0.05$ vs islet grafts from normal rats for each gene

$* * p<0.01$ vs islet grafts from normal rats for each gene

$* * * p<0.001$ vs islet grafts from normal rats for each gene were amplified with an internal control gene (cyclophilin A [Ppia], acidic ribosomal phosphoprotein P0 [Arbp], $\alpha$-tubulin [Tubal], TATA box binding protein $[T b p]$ or 18S rRNA) to correct for experimental variations between samples. Different control genes were used as required to match the amount of expression of the various tested genes. Specifically, Ppia was used for neurogenic differentiation 1 (Neurod1, also known as Beta 2 in other species), pancreatic and duodenal homeobox-1 ( $P d x 1)$, glucose transporter 2 (Glut2, also known as solute carrier family 2 [facilitated glucose transporter], member 2 [Slc2a2]), islet amyloid polypeptide (Iapp), glucagon and somatostatin; Arbp was used for paired box gene 6 (Рax 6$)$, NK6 transcription factor related, locus 1 (Nkx6.1) and the pore-forming subunit of the ATP-sensitive $\mathrm{K}^{+}$channel (potassium inwardly-rectifying channel, subfamily J, member $11, K c n j 11$; also known as Kir6.2); Tubal was used for glucokinase; Tbp was used for hexokinase-1, lactate dehydrogenase A (Ldha) and glucose6-phosphatase; and 18S rRNA was used for insulin. Amplimers were separated on $6 \%$ polyacrylamide gels in Tris-borate-EDTA buffer. The gel was dried and the amount of $\alpha-{ }^{32} \mathrm{P}$-labelled $\mathrm{dCTP}$ incorporated into amplimers was measured with a Storm 840 PhosphoImager and quantified with ImageQuant software (Molecular Dynamics, Sunnyvale, CA, USA). The average intensity of each product was expressed relative to the internal control gene (ratio of specific product:control gene). These ratios were then expressed as a percentage of the ratio in control samples. Control experiments were performed to adjust the PCR conditions such that the number of cycles used was in the exponential phase of amplification for all products and that each PCR product in a multiplex reaction increased linearly with the amount of starting material.

Immunohistochemistry At 18 days after implantation, grafts were excised under anaesthesia, trimmed of extraneous tissue and fixed in $4 \%(\mathrm{wt} / \mathrm{vol}$.) paraformaldehyde. After embedding in paraffin, $5 \mu \mathrm{m}$ sections were stained for insulin (guinea pig anti-human insulin, 1:200; Linco Research, St Charles, MO, USA), GLUT2 (rabbit anti-rat GLUT2, 1:400; Chemicon, Temecula, CA, USA) and NKX6.1 (1:500; gift of P. Serup, Hagedorn, Gentofe, Denmark). The secondary antibodies used for immunofluorescence were: for insulin, Texas Red conjugated affinipure donkey anti-guinea pig IgG (1:400; Jackson ImmunoResearch, West Grove, PA, USA); and for GLUT2 and NKX6.1, donkey biotinylated anti-rabbit IgG (1:400; Jackson ImmunoResearch) followed by streptavidin-conjugated FITC (1:400; Jackson ImmunoResearch). Images of the grafts were taken with a $\times 25$ objective with the same settings in the confocal mode of an LSM 410 microscope (Zeiss, Thornwood, NY, USA). Composite pictures of the grafts were composed in Adobe Photoshop. 
Statistical analysis All results are presented as means \pm SEM. Statistical analyses were performed using unpaired Student's $t$ test or one-way ANOVA with post hoc test of Fisher's protected least significant difference.

\section{Results}

Changes in gene expression in islet grafts from diabetic rats We tested the effects of continuous diabetes exposure on beta cell differentiation in transplanted islets by analysing renal subcapsular grafts of 2,000 syngeneic islets from normal (non-diabetic) or streptozotocin-induced diabetic rats. Eighteen days after transplantation, body weights of diabetic rats did not differ from those of normal rats, whereas blood glucose levels were significantly increased (Table 1). The expression of specialised islet-associated transcription factors, islet hormones and beta cell metabolic enzymes, as well as of other normally suppressed metabolic enzymes was compared in islet grafts retrieved from normal and diabetic rats. After normalisation of the gene of interest to a control gene, mRNA levels in diabetic grafts were quantitated as a percentage of normal grafts (Table 1). In islet grafts from diabetic rats mRNA levels of $P d x 1$, Neurod 1 and $N k x 6.1$ were reduced to $40 \%$ to $50 \%$ of normal and Pax6 was reduced further. Additionally, in islet grafts from diabetic rats, Glut2 and glucokinase, the enzyme responsible for the majority of beta cell glucose phosphorylation, were reduced to $64 \%$ and $50 \%$ of normal, respectively. Interestingly, Ldha and glucose-6-phosphatase, enzymes normally expressed at low levels in islets [19, 20], had significantly increased mRNA levels (Ldha) or a tendency to be increased (glucose-6-phosphatase; NS) in grafts from diabetic rats. However, hexokinase-1, which is upregulated in islets of other models of diabetes [19], was not altered in islet grafts from diabetic rats. The expression of a gene encoding an ion channel important for glucoseinduced insulin release, Kcnj11, showed a tendency to have decreased mRNA levels in grafts from diabetic rats. Insulin was markedly downregulated with diabetes; mRNA levels of only $16 \%$ of normal denote the most severely reduced transcript of those tested (Table 1), while that of the other beta cell hormone, Iapp, was only modestly reduced to $81 \%$ of normal (Table 1). Thus, exposure of transplanted islets to a prolonged period of diabetes is associated with a widespread disruption of gene expression in the form of decreased expression of a panel of genes that optimise GIIS and induction of several genes that are normally suppressed.

Effect of reversing diabetes on changes in gene expression in transplanted islets We tested the reversibility of the changes in mRNA levels by analysing islet grafts from diabetic rats transplanted with either a sufficient $(3,000)$ or an insufficient $(2,000)$ number of islets to normalise hyperglycaemia. Islets $(2,000)$ transplanted into normal rats were used as control. The time course changes in blood glucose levels after transplantation are shown in Fig. 1. Blood glucose levels were high in diabetic recipients on the day of transplantation (Fig. 1). Blood glucose levels of the rats transplanted with 3,000 islets gradually fell after transplantation, but, in contrast, remained elevated in diabetic rats receiving 2,000 islets. Although body weights were slightly lower in diabetic and diabetic-normalised rats than in normal rats, the rats in each group gained weight at a similar rate over the study period (Fig. 2).

Eighteen days after transplantation, mRNA levels were analysed in islet grafts retrieved from normal (2,000 islets), diabetic (2,000 islets) and diabetic-normalised (3,000 islets) rats. Strikingly, the normalisation of diabetes restored several of the islet-associated transcription factors towards the expression levels apparent in islet grafts from normal rats. Thus Neurod1 (Fig. 3a), Pax6 (Fig. 3b) and Nkx6.1 (Fig. 3c) mRNA levels were reduced in diabetic rats, but restored towards normal in diabetic-normalised rats. In contrast, $P d x 1$ mRNA levels (Fig. 3d) remained decreased in islet grafts from diabetic-normalised rats.

As shown in Fig. 4, the normalisation of diabetes at least partially reversed the changes in expression of glucose metabolism enzymes; reduced mRNA levels for Glut2 (Fig. 4a) and glucokinase (Fig. 4b) in islet grafts from diabetic rats were partially restored in diabetic-normalised rats. Downregulation of Glut2 has been previously identified in transplanted mouse islets [6] and other models of diabetes $[19,21,22]$; here we show that exposure to diabetes clearly contributes to its reduced expression in

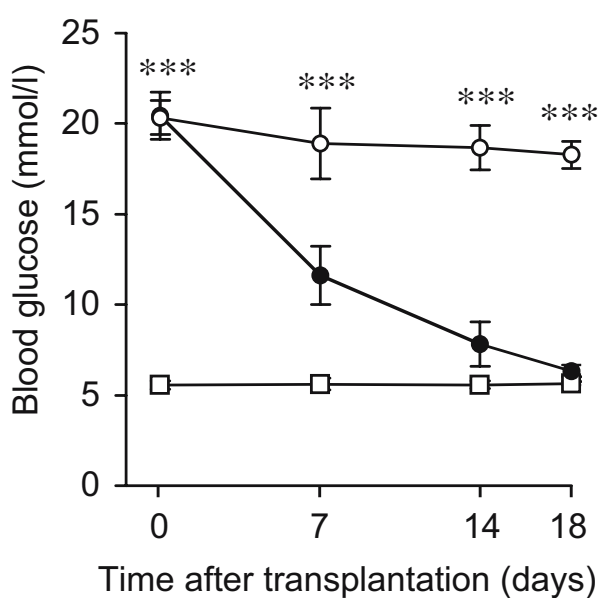

Fig. 1 Time-course changes in blood glucose levels after transplantation. Blood glucose levels were measured on days $0,7,14$ and 18 after transplantation. Normal rats were transplanted with 2,000 islets $(n=4$, squares) and diabetic rats with either 2,000 islets $(n=6$, open circles) or 3,000 islets ( $n=6$, closed circles). Results are means \pm SEM. $* p<0.05, * * * p<0.001 \mathrm{vs}$ normal at the same time point 


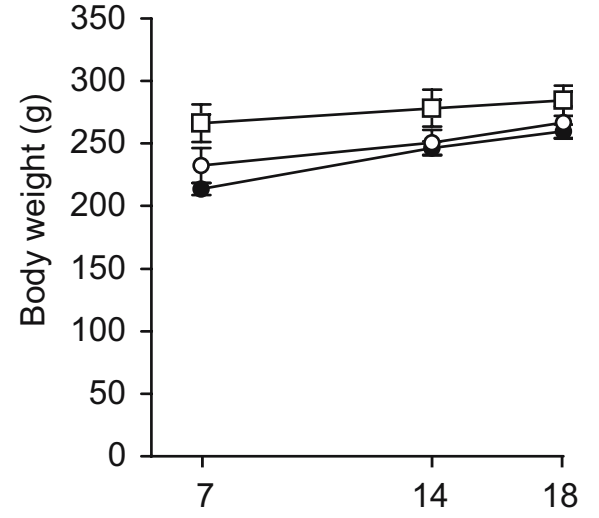

Time after transplantation (days)

Fig. 2 Time-course changes in body weight after transplantation. Body weights were measured on days 7,14 and 18 after transplantation. Normal rats were transplanted with 2,000 islets ( $n=4$, squares) and diabetic rats with either 2,000 islets ( $n=6$, open circles) or 3,000 islets ( $n=6$, closed circles). Results are means \pm SEM

transplanted rat islets. The mRNA levels of the $\mathrm{K}^{+}$channel subunit Kcnj11 were completely restored by reversing diabetes (Fig. 4c). Furthermore, there was a tendency for the increased mRNA levels of $L d h a$ to be partially reversed in diabetic-normalised rats (Fig. 4d). In contrast, glucose-6phosphatase mRNA levels were not reversed in islet grafts from diabetic-normalised rats (Fig. 4e).
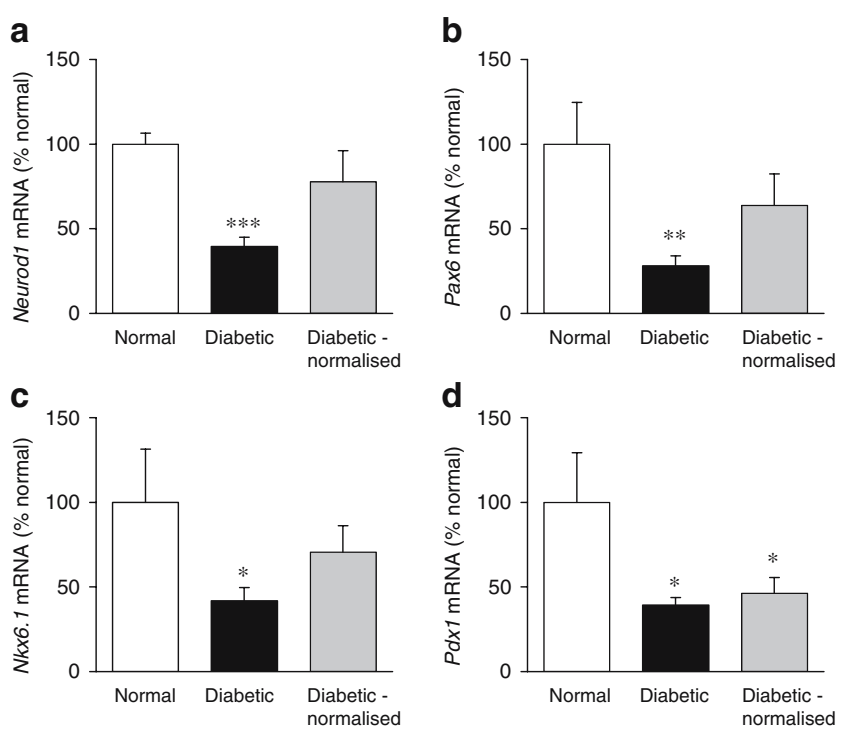

Fig. 3 Reversibility of changes in transcription factor mRNA levels in transplanted islets. mRNA levels were compared by semiquantitative multiplex RT-PCR in islet grafts from normal $(n=4)$, diabetic $(n=6)$ and diabetic-normalised rats $(n=6)$. mRNA levels are shown for the isletassociated transcription factors Neurod1 (a), Pax6 (b), Nkx6.1 (c) and $P d x I$ (d). After normalisation of the specific gene to a control gene, mRNA levels are expressed as a percentage of islet grafts from normal rats. Values are means \pm SEM. $* p<0.05, * * p<0.01$ and $* * * p<0.001$ vs islet grafts from normal rats for each gene
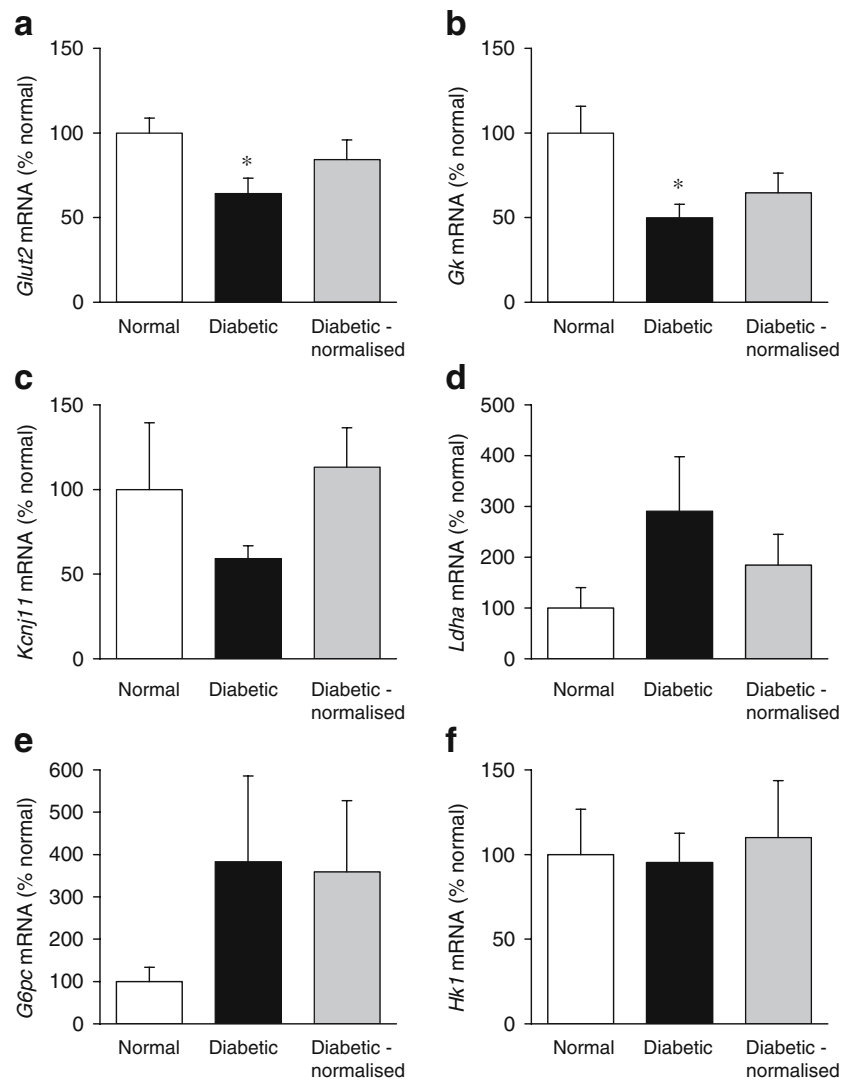

Fig. 4 Reversibility of changes in glucose metabolism and ion channel mRNA levels in transplanted islets. mRNA levels were compared as in Fig. 3 and are shown for $G l u t 2$ (a), glucokinase $(G k)(\mathbf{b})$, the $\mathrm{K}^{+}$channel subunit Kcnj11 (c), Ldha (d), glucose-6-phosphatase (G6pc) (e) and hexokinase $(H k l)$ (f). After normalisation of the specific gene to a control gene, mRNA levels are expressed as a percentage of islet grafts from normal rats. Values are means \pm SEM. ${ }^{*} p<0.05$ vs islet grafts from normal rats for each gene

As shown in Fig. 5a, insulin mRNA levels were partially reversed in islet grafts from diabetic-normalised rats, strongly suggesting an influence of the diabetic environment on the marked downregulation of insulin in transplanted islets. Similarly, Iapp mRNA levels were reversed in islet grafts from diabetic-normalised rats (Fig. 5b). Glucagon (Fig. 5c) and somatostatin (Fig. 5d) mRNA levels were not different in the grafts from normal, diabetic and diabetic-normalised groups, suggesting that hyperglycaemia specifically altered gene expression of the beta cell. Interestingly, Myc (myelocytomatosis viral oncogene homologue [avian], also known as c-myc) mRNA abundance, a molecular marker of altered beta cell proliferation and/or apoptosis, was not different in the grafts from normal, diabetic and diabetic-normalised groups (data not shown). Furthermore, based on our previous studies [10], we do not expect variations in cell death among the groups at this time point, although this was not assessed in the present study. The results of this study were not due to variable contamination with kidney tissue in the excised 

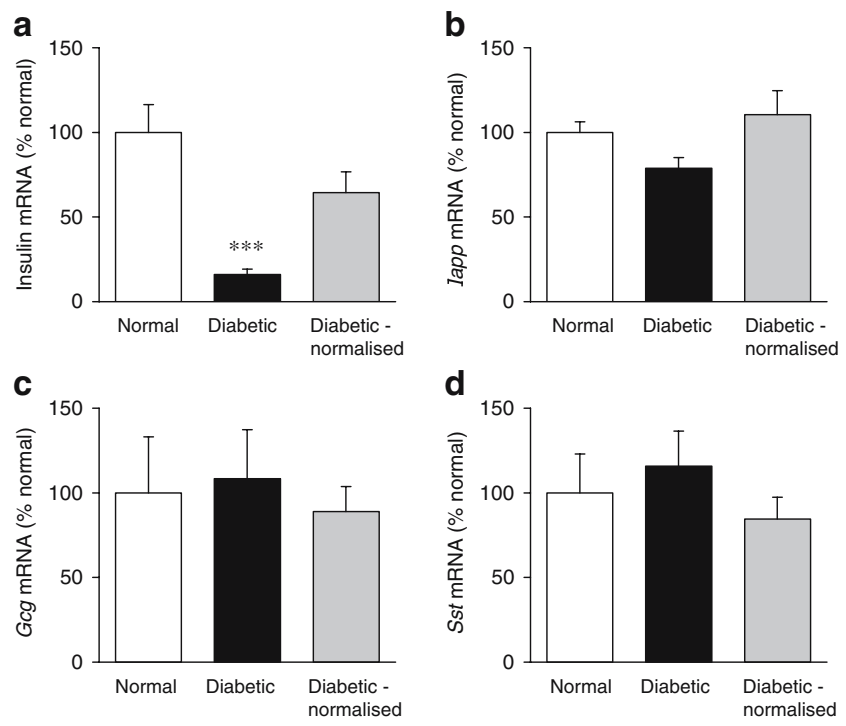

Fig. 5 Reversibility of changes in islet hormone mRNA levels in transplanted islets. mRNA levels were compared as in Fig. 3 and are shown for insulin (a), Iapp (b), glucagon $(G c g)$ (c) and somatostatin $(S s t)$ (d). After normalisation of the specific gene to a control gene, mRNA levels are expressed as a percentage of islet grafts from normal rats. Values are means \pm SEM. ${ }^{* * *} p<0.001$ vs islet grafts from normal rats for each gene

grafts. Expression of the kidney specific marker, Slc22a6, was used to determine the percentage of kidney contamination in each islet graft. Slc22a6 mRNA levels were low and not significantly different among the groups $(0.8 \pm$ $0.4 \%, 1.3 \pm 0.5 \%$ and $1.3 \pm 0.6 \%$ kidney in islet grafts from normal, diabetic and diabetic-normalised rats, respectively).

Sections of 18-day-old islet grafts from diabetic (Fig. 6a) and diabetic-normalised (Fig. 6b) rats were stained for insulin. Immunostaining for insulin was clearly more
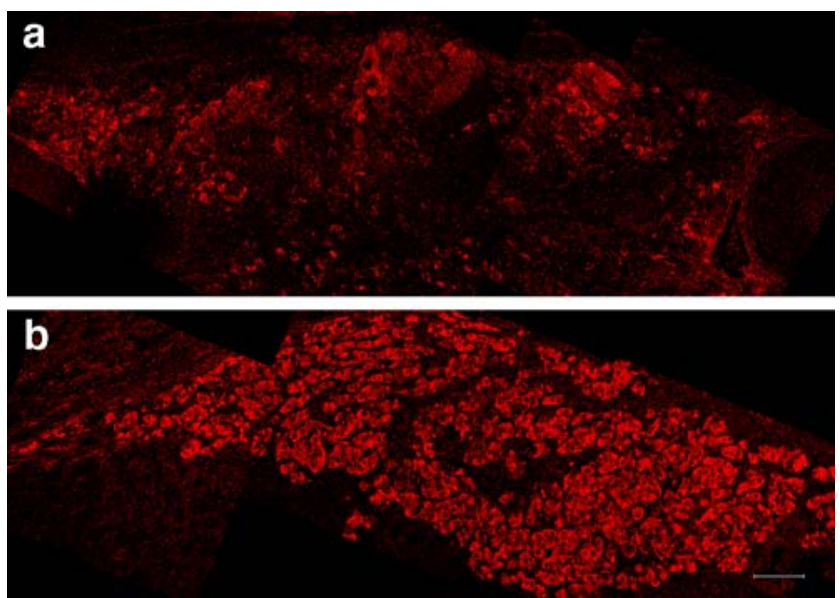

Fig. 6 Islet grafts show variable intensities of insulin immunostaining. Grafts from rats exposed to continuous diabetes have partially degranulated beta cells (a) as seen by the decreased intensity of the insulin (Texas red) immunostaining, which is far weaker than that in grafts after restoration of normoglycaemia (b). Magnification bar= $100 \mu \mathrm{m}$ intense in the beta cells of the graft retrieved after restoration of normoglycaemia (Fig. 6b) than in the beta cells that were continuously exposed to diabetes (Fig. 6a). Similarly, immunostaining for GLUT2 was present in the beta cells of the graft retrieved after restoration of normoglycaemia (Fig. 7a,c), compared with minimal staining in the beta cells that were continuously exposed to diabetes (Fig. 7b,d). In addition, typical nuclear NKX6.1 staining was visible in the beta cells of the graft retrieved from diabetic-normalised rats (Fig. 8a), but was virtually absent in beta cells of diabetic rats (Fig. 8b).

Comparison of islet-associated transcription factor and beta cell function mRNA levels between fresh islets and islet grafts RT-PCR analysis was performed to compare gene expression between fresh isolated islets and 18-day-old islet grafts retrieved from under the kidney capsule of normal rats. Expression of specific genes was normalised to their internal control gene and quantified as a percentage of those from fresh islets (Table 2). In comparison with fresh islets, islet grafts from normal rats exhibited markedly decreased mRNA levels of the transcription factor Pax6 $(p<0.05)$ and a tendency for Neurod 1 and $N k x 6.1$ to be reduced (NS). In contrast, $P d x 1$ mRNA levels were not different between
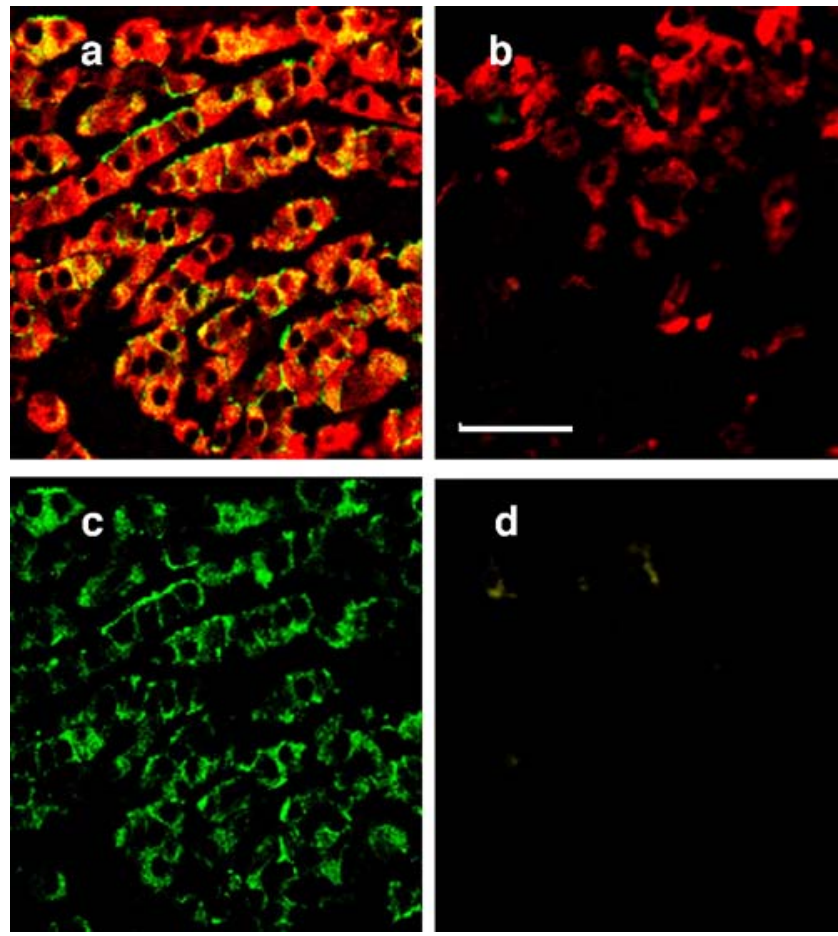

Fig. 7 Islet grafts show variable intensities of GLUT2 immunostaining. Immunostaining for GLUT2 (green) (a-d) is shown alone (c, d) or with insulin (red) (a, b). Grafts retrieved after restoration of normoglycaemia (a, c) show bright GLUT2 staining, typical of plasma membranes. In comparison, GLUT2 staining was markedly diminished in grafts exposed to continuous diabetes $(\mathbf{b}, \mathbf{d})$. Magnification bar $=50 \mu \mathrm{m}$ 

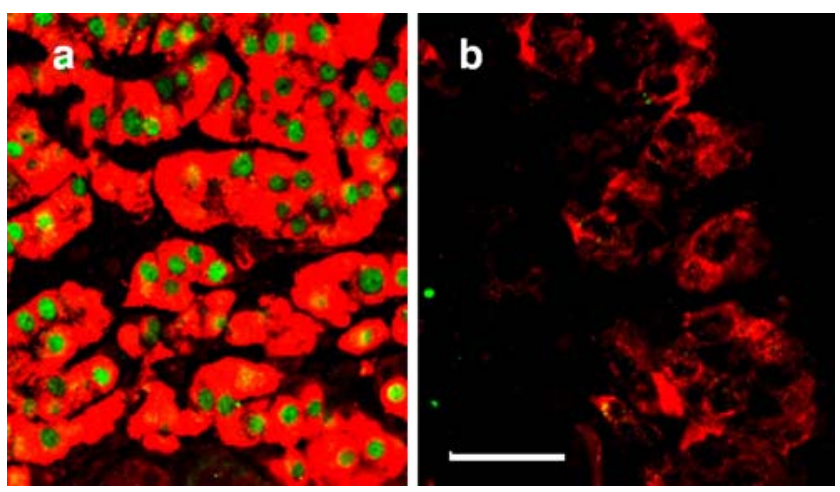

Fig. 8 NKX6.1 staining (green) is typically nuclear in beta cells of the graft retrieved from diabetic-normalised rats (a) compared with an absence of staining in beta cells from diabetic rats (b). Red, insulin staining. Magnification bar $=50 \mu \mathrm{m}$

fresh islets and transplanted islets (Table 2). Of the glucose metabolism enzymes tested, Glut2 and glucokinase had significantly reduced mRNA levels or a tendency (NS) for mRNA levels to be reduced respectively in islet grafts compared with fresh islets. In contrast, Ldha mRNA levels were slightly increased in islet grafts, although nonsignificantly. Hexokinase-1 and glucose-6-phosphatase mRNA levels were not different between fresh islets and transplanted islets. mRNA levels of the $\mathrm{K}^{+}$channel subunit Kcnj11 were markedly reduced in islet grafts. Furthermore, insulin $(p=0.06)$ and Iapp mRNA levels were reduced in islet grafts compared with freshly isolated islets. These data show that in comparison with fresh islets, islets transplanted

Table 2 Comparison of islet-associated transcription factor and beta cell function mRNA levels in fresh islets and islet grafts from normal rats

\begin{tabular}{lll}
\hline & Fresh islets & Islet grafts \\
\hline $\begin{array}{ll}\text { Transcription factors } \\
\text { Neurod1 }\end{array}$ & $100 \pm 28$ & $68 \pm 4$ \\
Pdx1 & $100 \pm 17$ & $110 \pm 37$ \\
Pax6 & $100 \pm 20$ & $34 \pm 8^{*}$ \\
Nkx6.1 & $100 \pm 18$ & $66 \pm 21$ \\
Metabolism & $100 \pm 4$ & \\
Glut2 & $100 \pm 15$ & $67 \pm 6^{* *}$ \\
Glucokinase & $100 \pm 21$ & $67 \pm 11$ \\
Hexokinase-1 & $100 \pm 19$ & $97 \pm 26$ \\
Ldha & $100 \pm 42$ & $166 \pm 36$ \\
Glucose-6-phosphatase & & $124 \pm 42$ \\
Ion channel & $100 \pm 6$ & $31 \pm 12^{* *}$ \\
Kcnj11 & & \\
Hormones & $100 \pm 11$ & $62 \pm 10$ \\
Insulin & $100 \pm 4$ & $74 \pm 5^{*}$ \\
Iapp & $100 \pm 15$ & $18 \pm 8^{* *}$ \\
Glucagon & $100 \pm 23$ & $18 \pm 6^{*}$ \\
Somatostatin &
\end{tabular}

Values are means \pm SEM determined from three to four experiments and are expressed as a percentage of mRNA levels in fresh islets $* p<0.05$ vs isolated islets for each gene

$* * p<0.01$ vs isolated islets for each gene into a normoglycaemic environment display a few significant alterations of beta cell gene expression. Interestingly, both glucagon and somatostatin mRNA levels were markedly reduced in normal grafts compared with fresh islets (Table 2). These findings are consistent with data showing that transplanted rat islets lose many of their nonbeta cells within 2 to 3 weeks post transplantation (King et al., unpublished data).

\section{Discussion}

Using an islet transplantation model, we show that exposure of beta cells to diabetes is associated with a widespread disruption of gene expression in the form of decreased expression of a panel of genes that optimise GIIS and induction of several genes that are normally suppressed. We also found that islets transplanted into a normoglycaemic environment show some alterations in the expression of genes involved in insulin secretion when compared with fresh islets, whereas a marked deterioration in graft beta cell differentiation was associated with chronic exposure to hyperglycaemia. These data support the hypothesis that hyperglycaemia in the post islet transplantation period leads to a loss of the unique expression pattern of genes responsible for maintaining GIIS, thus adversely influencing transplant outcomes.

The disruption of beta cell gene expression in islet grafts continuously exposed to hyperglycaemia can be correlated with a loss of GIIS from the graft-bearing kidney [6, 7]. Furthermore, the restoration of beta cell gene expression in islet grafts after normalisation of glucose levels correlates with normal biphasic GIIS [6, 7]. In several animal models of hyperglycaemia and type 2 diabetes, such as the $d b / d b$ mouse, Zucker diabetic fatty rat and partially pancreatectomised (Px) rat, studies have found a similar phenomenon of loss of differentiation associated with beta cell dysfunction $[19,21,23,24]$. Common to these models is a decreased expression of genes important for glucosestimulated insulin secretion, beta cell development and the regulation of beta cell gene expression. mRNA levels of several transcription factors important for the maintenance of beta cell differentiation (Pdxl, Neurodl, Nkx6.1 and Pax6) were reduced in transplanted islets in the present study and in endogenous islets from rodent diabetes models $[19,23,24]$. The decreased expression of these islet transcription factors could contribute to the parallel downregulation of genes essential for GIIS, such as Glut2, glucokinase, the $\mathrm{K}^{+}$channel subunit Kcnj11 and insulin [25-27]. Interestingly, in transplanted islets from diabetic rats, insulin was more severely decreased than the other genes tested (Table 1). This contrasts with findings in $d b / d b$ 
mice [24] and Px rats [19, 23], in which insulin mRNA levels were preserved or decreased to a lesser degree, compared with expression changes of numerous glucosesensing genes and islet transcription factors.

The majority of the gene expression changes in islet grafts from diabetic rats were completely, or at least partially, prevented (or reversed) in transplanted islets from rats in which diabetes was cured. The notable exception was the expression of $P d x l$, which remained largely suppressed, a finding that could be due to effects of the initial period of hyperglycaemia after transplantation. The delay in normalisation of blood glucose levels may have been due to the time required for vascularisation and recovery from hypoxia and nutrient deprivation [28-30]. In addition, minor residual hyperglycaemia at the time of graft retrieval could have an influence; even minimal levels of hyperglycaemia can have a dramatic impact on beta cell gene expression in the long term [23].

The loss of function of an islet graft is a major obstacle to the success of islet transplantation. We have shown that transplanted islets display an alteration in normal expression of several genes necessary for optimal GIIS. Some alterations were even found in successful transplants, but they were far more severe in grafts exposed to hyperglycaemia. This deterioration in beta cell differentiation may be a major factor in the impaired insulin secretion that accompanies poor transplant outcomes. Thus, hyperglycaemia may produce a dangerous spiral of deficient insulin secretion that leads to even higher glucose levels that can then produce even worse secretion and perhaps even accelerate beta cell death. An understanding of these molecular events should help us develop strategies that could improve transplant outcomes, such as a more aggressive maintenance of normoglycaemia in the peri-transplant period.

Acknowledgements This work was supported by grants from the National Institutes of Health (DK50657, U19DK6125), the Juvenile Diabetes Research Foundation and the Diabetes Research and Wellness Foundation. Help was also provided by the Joslin Diabetes and Endocrinology Research Center supported by the National Institutes of Health (DK36836). D. R. Laybutt was a recipient of a Career Development Award and a grant from the National Health and Medical Research Council of Australia. Y. C. Hawkins was supported by the Medical Scholars Program of the American Diabetes Association. Y. C. Hawkins also received a Research Supplement for Underrepresented Minorities for P01 DK53087 from the National Institutes of Health.

Duality of interest The authors declare that there is no duality of interest associated with this manuscript.

\section{References}

1. Brunzell JD, Robertson RP, Lerner RL et al (1976) Relationships between fasting plasma glucose levels and insulin secretion during intravenous glucose tolerance tests. J Clin Endocrinol Metab 42:222-229
2. Porte D Jr (1991) Beta-cells in type II diabetes mellitus. Diabetes 40:166-180

3. McCulloch DK, Klaff LJ, Kahn SE et al (1990) Nonprogression of subclinical beta-cell dysfunction among first-degree relatives of IDDM patients. 5-yr follow-up of the Seattle Family Study. Diabetes 39:549-556

4. Eisenbarth GS (1986) Type I diabetes mellitus. A chronic autoimmune disease. N Engl J Med 314:1360-1368

5. Gray DW, Cranston D, McShane P, Sutton R, Morris PJ (1989) The effect of hyperglycaemia on pancreatic islets transplanted into rats beneath the kidney capsule. Diabetologia 32:663-667

6. Ogawa Y, Noma Y, Davalli AM et al (1995) Loss of glucoseinduced insulin secretion and GLUT2 expression in transplanted beta-cells. Diabetes 44:75-79

7. Korsgren O, Jansson L, Sandler S, Andersson A (1990) Hyperglycemia-induced B cell toxicity. The fate of pancreatic islets transplanted into diabetic mice is dependent on their genetic background. J Clin Invest 86:2161-2168

8. Shapiro AM, Lakey JR, Ryan EA et al (2000) Islet transplantation in seven patients with type 1 diabetes mellitus using a glucocorticoidfree immunosuppressive regimen. N Engl J Med 343:230-238

9. Alejandro R, Cutfield RG, Shienvold FL et al (1986) Natural history of intrahepatic canine islet cell autografts. J Clin Invest 78:1339-1348

10. Davalli AM, Scaglia L, Zangen DH, Hollister J, Bonner-Weir S, Weir GC (1996) Vulnerability of islets in the immediate posttransplantation period. Dynamic changes in structure and function. Diabetes 45:1161-1167

11. Mattsson G, Jansson L, Nordin A, Andersson A, Carlsson PO (2004) Evidence of functional impairment of syngeneically transplanted mouse pancreatic islets retrieved from the liver. Diabetes 53:948-954

12. Montana E, Bonner-Weir S, Weir GC (1993) Beta cell mass and growth after syngeneic islet cell transplantation in normal and streptozotocin diabetic C57BL/6 mice. J Clin Invest 91:780-787

13. Shi CL, Taljedal IB (1996) Dynamics of glucose-induced insulin release from mouse islets transplanted under the kidney capsule. Transplantation 62:1312-1318

14. Ryan EA, Paty BW, Senior PA et al (2005) Five-year follow-up after clinical islet transplantation. Diabetes 54:2060-2069

15. Juang JH, Bonner-Weir S, Wu YJ, Weir GC (1994) Beneficial influence of glycemic control upon the growth and function of transplanted islets. Diabetes 43:1334-1339

16. Ar'Rajab A, Ahren B (1992) Prevention of hyperglycemia improves the long-term result of islet transplantation in streptozotocin-diabetic rats. Pancreas 7:435-442

17. Biarnes M, Montolio M, Nacher V, Raurell M, Soler J, Montanya E (2002) Beta-cell death and mass in syngeneically transplanted islets exposed to short- and long-term hyperglycemia. Diabetes 51:66-72

18. Lopez-Nieto CE, You G, Bush KT, Barros EJ, Beier DR, Nigam SK (1997) Molecular cloning and characterization of NKT, a gene product related to the organic cation transporter family that is almost exclusively expressed in the kidney. J Biol Chem 272: 6471-6478

19. Jonas JC, Sharma A, Hasenkamp W et al (1999) Chronic hyperglycemia triggers loss of pancreatic beta cell differentiation in an animal model of diabetes. J Biol Chem 274:14112-14121

20. Laybutt DR, Sharma A, Sgroi DC, Gaudet J, Bonner-Weir S, Weir GC (2002) Genetic regulation of metabolic pathways in beta-cells disrupted by hyperglycemia. J Biol Chem 277:10912-10921

21. Tokuyama Y, Sturis J, DePaoli AM et al (1995) Evolution of betacell dysfunction in the male Zucker diabetic fatty rat. Diabetes 44:1447-1457

22. Thorens B, Wu YJ, Leahy JL, Weir GC (1992) The loss of GLUT2 expression by glucose-unresponsive beta cells of $\mathrm{db} / \mathrm{db}$ 
mice is reversible and is induced by the diabetic environment. J Clin Invest 90:77-85

23. Laybutt DR, Glandt M, Xu G et al (2003) Critical reduction in beta-cell mass results in two distinct outcomes over time. Adaptation with impaired glucose tolerance or decompensated diabetes. J Biol Chem 278:2997-3005

24. Kjorholt C, Akerfeldt MC, Biden TJ, Laybutt DR (2005) Chronic hyperglycemia, independent of plasma lipid levels, is sufficient for the loss of beta-cell differentiation and secretory function in the $\mathrm{db} / \mathrm{db}$ mouse model of diabetes. Diabetes 54:2755-2763

25. Huang HP, Tsai MJ (2000) Transcription factors involved in pancreatic islet development. J Biomed Sci 7:27-34

26. Schwitzgebel VM, Scheel DW, Conners JR et al (2000) Expression of neurogenin3 reveals an islet cell precursor population in the pancreas. Development 127:3533-3542
27. Servitja JM, Ferrer J (2004) Transcriptional networks controlling pancreatic development and beta cell function. Diabetologia 47:597-613

28. Menger MD, Jaeger S, Walter P, Feifel G, Hammersen F, Messmer K (1989) Angiogenesis and hemodynamics of microvasculature of transplanted islets of Langerhans. Diabetes 38 (Suppl 1):199-201

29. Vasir B, Reitz P, Xu G, Sharma A, Bonner-Weir S, Weir GC (2000) Effects of diabetes and hypoxia on gene markers of angiogenesis (HGF, cMET, uPA and uPAR, TGF- $\alpha$, TGF- $\beta$, $\mathrm{bFGF}$ and vimentin) in cultured and transplanted rat islets. Diabetologia 43:763-772

30. Dionne KE, Colton CK, Yarmush ML (1993) Effect of hypoxia on insulin secretion by isolated rat and canine islets of Langerhans. Diabetes 42:12-21 